\title{
O brincar por meio do lúdico na educação infantil de forma inclusiva
}

\author{
The Play through play in early childhood education in na inclusive way \\ Jugar a través del juego em la educación infantil de forma inclusiva
}

Recebido: 29/09/2021 | Revisado: 04/10/2021 | Aceito: 06/10/2021 | Publicado: 10/10/2021

Luandson Luis da Silva

ORCID: https://orcid.org/0000-0001-7422-2042 Universidade Estadual da Paraíba, Brasil

E-mail: professorluandsonluis@gmail.com

Samilly dos Santos Bernardo Luis

ORCID: https://orcid.org/0000-0001-5316-3629

Faculdade Três Marias, Brasil

E-mail: samillybernardoluis@gmail.com

Joelson Francisco Gomes

ORCID: https://orcid.org/0000-0001-6143-7618 Universidade Estadual da Paraíba, Brasil

E-mail: joellgonmes61@gmail.com

Damião Cavalcante do Nascimento

ORCID: https://orcid.org/0000-0002-2538-0500 Universidade Estadual da Paraíba, Brasil E-mail: dammiao.cavalcante@gmail.com

Maria da Vitória Gomes

ORCID: https://orcid.org/0000-0002-0422-8198 Universidade Estadual da Paraíba, Brasil E-mail: mariavitoriagomes018@gmail.com

\begin{abstract}
Resumo
Este trabalho bibliográfico, em formato de artigo, apresenta em seus escritos algumas concepções educacionais frente à ludicidade na educação infantil de forma inclusiva. Para tanto, o mesmo está ancorado nas fundamentações teóricas de alguns autores, como: Almeida (1974); Barbosa (2006); Bossa (2007); Medeiros (2000); Negrini (1994); Piaget (1979); Ramos (2011); Rojas (2006); Velasco (2006); Rego (2011); Café (2018), Lyra (2019); Ferreira (2020), além de documentos legais e diretrizes educativas e outros teóricos, que em seus estudos contribuem com as discussões aqui estabelecidas. $\mathrm{O}$ artigo em estudo conta com um objetivo geral que consiste em analisar o papel do professor na Educação Infantil por meio da ludicidade nos estabelecimentos de ensino de forma inclusiva. O trabalho justifica-se pela necessidade de apresentar no meio acadêmico produções que versem sobre a temática abordada pelo título do trabalho. Metodologicamente, faremos uso de uma abordagem qualitativa, de caráter bibliográfico com respaldos em fontes secundárias de informações. Nesse elo educacional, compreende-se a ludicidade como um processo multifacetado de desenvolvimento da aprendizagem, que necessita a todo tempo de um envolvimento didático repleto de atividades diversificadas, além de jogos e brincadeiras infantis na ótica do educar, do cuidar e do brincar.
\end{abstract}

Palavras-chave: O lúdico na educação infantil; Jogos e brincadeiras; Inclusão.

\begin{abstract}
This bibliographical work, in article format, presents in its writings some educational conceptions regarding playfulness in early childhood education in an inclusive way. Therefore, it is anchored in the theoretical foundations of some authors, such as: Almeida (1974); Barbosa (2006); Bossa (2007); Medeiros (2000); Negrini (1994); Piaget (1979); Ramos (2011); Rojas (2006); Velasco (2006); Rego (2011); Café (2018), Lyra (2019); Ferreira (2020), in addition to legal documents and educational and other theoretical guidelines, which in their studies contribute to the discussions established here. The article under study has a general objective which is to analyze the role of the teacher in early childhood education through playfulness in educational establishments in an inclusive way. The work is justified by the need to present in the academic environment productions that deal with the theme addressed by the title of the work. Methodologically, we will make use of a qualitative approach, with a bibliographic character, supported by secondary sources of information. In this educational link, playfulness is understood as a multifaceted process of learning development, which requires at all times a didactic involvement full of diversified activities, in addition to children's games and games from the perspective of educating, caring and playing.
\end{abstract}

Keywords: The playful in early childhood education; Games and games; Inclusion. 


\begin{abstract}
Resumen
Este trabajo bibliográfico, en formato de artículo, presenta en sus escritos algunas concepciones educativas sobre el lúdico en la educación infantil de manera inclusiva. Por tanto, se ancla en los fundamentos teóricos de algunos autores, como: Almeida (1974); Barbosa (2006); Bossa (2007); Medeiros (2000); Negrini (1994); Piaget (1979); Ramos (2011); Rojas (2006); Velasco (2006); Rego (2011); Café (2018), Lyra (2019); Ferreira (2020), además de documentos legales y orientaciones educativas y teóricas, que en sus estudios contribuyen a las discusiones aquí establecidas. El artículo en estudio tiene un objetivo general que es analizar el papel del docente en la educación infantil a través del juego lúdico en los establecimientos educativos de manera inclusiva. El trabajo se justifica por la necesidad de presentar en el ámbito académico producciones que abordan el tema abordado por el título del trabajo. Metodológicamente, haremos uso de un enfoque cualitativo, de carácter bibliográfico, apoyado en fuentes de información secundarias. En este vínculo educativo, el lúdico se entiende como un proceso multifacético de desarrollo del aprendizaje, que requiere en todo momento una implicación didáctica llena de actividades diversificadas, además de juegos y juegos infantiles desde la perspectiva de educar, cuidar y jugar.
\end{abstract}

Palabras clave: Lo lúdico em la educación infantil; Juegos y juegos; Inclusión.

\title{
1. Introdução
}

Este artigo de caráter bibliográfico apresenta fundamentações teóricas relevantes aos sistemas e concepções educacionais. O mesmo, tem como tema “O Brincar Por Meio Do Lúdico Na Educação Infantil De Forma Inclusiva” e realça, em seus capítulos, concepções educativas de extrema relevância para o meio acadêmico de maneira crítica e reflexiva.

O trabalho está ancorado nas fundamentações teóricas de alguns autores como: Almeida (1974); Barbosa (2006); Bossa (2007); Medeiros (2000); Negrini (1994); Piaget (1979); Ramos (2011); Rojas (2006); Velasco (2006); Rego (2011); Café (2018), Lyra (2019); Ferreira (2020), além de documentos legais e diretrizes educativas e outros teóricos, que em seus estudos contribuem com as discussões aqui estabelecidas.

$\mathrm{O}$ artigo em estudo conta com um objetivo geral que consiste em analisar a atuação do professor frente à educação infantil por meio da ludicidade nos estabelecimentos de ensino de forma inclusiva. O trabalho justifica-se pela necessidade de apresentar no meio acadêmico produções que versem sobre a temática abordada pelo título do trabalho.

Nesse elo educacional, compreende-se a ludicidade como um processo multifacetado de desenvolvimento da aprendizagem, que necessita a todo tempo de um envolvimento didático repleto de atividades diversificadas, além de jogos e brincadeiras infantis na ótica do educar do cuidar e do brincar.

Dessa forma, devemos analisar todo o processo de ensino e aprendizagem com cautela, pois durante esse processo a criança desenvolve suas capacidades afetivas, cognitivas e motoras, e qualquer deslize cometido pelos profissionais da instituição escolar, principalmente pelo professor, pode afetar seu desenvolvimento durante a educação infantil.

As escolas estão buscando, embora que de modo vagaroso, orientar o corpo docente a utilizarem o Jogo, a ludicidade, como ferramenta didática no cotidiano escolar como estratégia de aprendizagem para as crianças. No entanto, é necessário que as atividades lúdicas não sejam utilizadas de qualquer maneira, mas que sejam pensadas, planejadas e desenvolvidas visando a transformação das práticas educativas vigentes.

Além dessa seção introdutória, este artigo está dividido em quatro unidades retóricas, as quais obedecem à seguinte ordem: inicialmente, discutimos sobre a abordagem metodológica que utilizaremos para o desenvolvimento desta pesquisa. Em seguida, abordamos acerca do ato do brincar na Educação Infantil visando o fato da inclusão. Prosseguiremos abordando acerca das concepções da ludicidade como ferramenta de aprendizagem.

Ademais, na quinta seção, apresentamos brevemente estudos que versam sobre a motivação e a importância do brincar na infância. Na sexta unidade retorica, versamos sobre a realidade educacional no que se refere aos jogos didáticos, prosseguindo com a abordagem, na sétima seção, no que diz respeito à relevância dos jogos e da ludicidade na Educação Infantil. Por último, apresentamos algumas considerações acerca da pesquisa neste estudo realizada e as referências utilizadas 
como respaldos teóricos e argumentativos.

\section{Metodologia}

Em termos metodológicos, este trabalho segue um paradigma bibliográfico, dado que priorizaremos a análise da teoria de várias literaturas, portanto, é uma pesquisa de natureza bibliográfica, visando à otimização deste trabalho. A esse respeito, Medeiros (2000) defende que:

A pesquisa bibliográfica é caracterizada pela utilização de fontes secundárias, ou seja, pela identificação e análises dos dados escritos em livros, artigos de revistas, dentre outros. Sua finalidade é colocar o investigador em contato com que já se produzia a respeito do seu tema de pesquisa (Medeiros, 2000, p.40).

Nesse sentido, os dados para análise serão resultantes de pesquisas em periódicos científicos, leituras de artigos já publicados em plataformas académicas digitais, tais como: Google acadêmico, Biblioteca Digital Brasileira de Teses e Dissertações (BDTD) e livros.

Ademais, a natureza da abordagem é qualitativa, uma vez que esse tipo de abordagem "depende de muitos fatores, tais como a natureza dos dados coletados, a extensão da amostra, os instrumentos de pesquisa e os pressupostos teóricos que nortearam a investigação" (Gil, 2002, p. 133).

Para tanto, entendemos que para desenvolver um bom projeto, todo pesquisador deve estar atento aos seguintes requisitos básicos: formular o problema, enunciar as hipóteses, definir os termos do problema e das hipóteses, estabelecer as bases teóricas e perceber as relações existentes entre estas. Ainda é preciso analisar a formulação do problema e enunciado das hipóteses, observando as consequências para o fato real e teórico e se as hipóteses serão aceitas ou não.

\section{Educação Infantil: o brincar de forma inclusiva}

As brincadeiras são de fundamental importância para o desenvolvimento da criança, uma vez que sem elas o desenvolvimento fica incompleto. Nesse sentido, as crianças precisam do lúdico de modo inclusivo, para se desenvolverem integralmente e garantirem seu espaço na sociedade contemporânea que resguarda os direitos legais das crianças por meio das legislações vigentes.

Acerca disso, a Lei de Diretrizes e Bases da Educação Nacional (LDB), estabelecida pela Lei no 9.394/1996, defende a educação como um direito subjetivo e, também, definem a Educação Infantil como sendo a primeira etapa da Educação Básica e objetiva promover o desenvolvimento integral da criança, em parceria com a ação da família e a comunidade. Desse modo: "Art. 29. A educação infantil, primeira etapa da educação básica, tem como finalidade o desenvolvimento integral da criança de até 5 (cinco) anos, em seus aspectos físico, psicológico, intelectual e social, complementando a ação da família e da comunidade" (Brasil, 1996, p. 22).

O Referencial Curricular para a Educação Infantil - RCNEI (1998) foi realizado diante de um longo debate nacional, com a participação de professores e diversos profissionais que atuam diretamente com crianças, contribuindo de forma significativa para orientar a prática pedagógica, incluindo a tríade em que deve ser realizado o trabalho na Educação Infantil que é: cuidar, educar e brincar. Logo a ludicidade ganha destaque e permeia todo o processo de aprendizagem da criança, especialmente no que tange às séries iniciais da educação.

Nesse viés, entende-se que o lúdico é uma ferramenta motivadora da aprendizagem dos alunos. A forma como os conteúdos são trabalhados através do lúdico os tornam mais atrativos para os alunos. Desse modo, o lúdico pode auxiliar na intervenção psicopedagógica de forma complementar à ação em sala de aula, tornando as atividades mais prazerosas e significativas. Somente assim, o discente pode experimentar as possibilidades do amadurecimento, livre da ansiedade ou do 
medo que inibem sua ação. Em seu estudo, Negrini (1994, p. 20) ressalta que: "quando a criança vem à escola, traz consigo toda uma pré-história, construída a partir de suas vivências, grande parte delas através da atividade lúdica".

À vista disso, o autor defende que quando a criança vai para a escola, ela já aprendeu, em sua casa e em sua comunidade, em convivência com outros indivíduos, aquilo que a torna apta para iniciar o tipo de aprendizagem mais sistematizada que a escola propõe. Mas, é preciso nos atentarmos para essa aprendizagem desenvolvida fora da escola, pois ela depende de vários fatores, dentre os quais destacamos a confiança que a criança tem na aceitação e na proteção dos pais.

Diante disso, a aprendizagem significativa é o meio pelo qual a criança se apropria dos saberes práticos e concretos, saberes estes que lhe são próprios culturalmente e lhe acompanhará por todo o percurso escolar fundamental ao desenvolvimento psíquico. A interação com seus pares e adultos também facilita a aprendizagem. Acerca disso, desde o seu nascimento, a criança vai, gradativamente, ampliando suas formas de lidar com o mundo e construindo significados para as suas ações e para as experiências que vive.

Durante as interações proporcionadas pelos jogos é que se desenvolve o respeito mútuo entre adultos e crianças e entre criança-criança dentro de um clima afetivo em que ela tem a oportunidade de construir seu conhecimento social, físico e cognitivo estruturando sua inteligência e interação com meio em que está inserida (Lyra, 2019, p. 4).

Logo, a aprendizagem procede do meio social e cultural do aprendiz e este fato deve dar suporte para o professor para que ele perceba o perfil individual e coletivo do aluno, bem como da comunidade onde a escola está situada, isto lhe possibilitará traçar melhores planejamentos e desenvolver melhores práticas pedagógicas.

Para tanto, embora seja de suma importância a ação do profissional, isto é, do professor, não se deve colocar toda a responsabilidade do processo de aprendizagem dos alunos única e exclusivamente sobre os ombros deste, uma vez que ele não é o único responsável pelo sucesso ou fracasso do processo educativo dos discentes. É preciso, pois, que tenhamos a consciência de que esse dever também é responsabilidade da família, amigos, sociedade, sistemas educacionais (secretarias, escola, etc.), assim, ocorrerá a oferta de uma educação de qualidade.

\section{O Lúdico como Ferramenta Facilitadora no Processo de Aprendizagem de Maneira Inclusiva}

O lúdico além de facilitar a visão da relação da criança sobre o social, ainda pode promover o resgate das influências culturais e, por sua vez, torna a escola como um espaço de resgate cultural e inclusivo, de valorização social, de reprodução do conhecimento adquirido em gerações passadas, além de transpor a emoção do imaginário infantil. "A ludicidade é passível de observação, de descrição, de explicação, de descobertas, portanto, no seu processo de ser ludicidade também é possível produzir conhecimentos a partir dos elementos internos e externos manifestados, das experiências" (Ferreira, 2020, p. 418).

O lúdico acontece de maneira natural e espontânea. Assim, o imaginário, o fazer acontecer, a criatividade, o faz de conta possibilita que a aprendizagem ocorra de forma significativa, através de uma perspectiva de aprendizagem prazerosa, dinâmica e objetiva, onde a criança se dispõe a construir o conhecimento de forma "inconsciente", porém, diversificada.

Diante disso, o professor, enquanto mediador do conhecimento, exerce apenas a função de intermediar o processo e observar as brincadeiras que podem facilitar a assimilação do que é proposto e a evolução dos aspectos cognitivos de seus alunos. Dessa forma, a atividade acaba por ser prazerosa e sem a imposição de limites e de regras abstratas. Nesse sentido: "Para a criança, a brincadeira gira em torno da espontaneidade e da imaginação. Não depende de regras, de formas rigidamente estruturadas. Para surgir basta uma bola, um espaço para correr ou um risco no chão" (Velasco, 2006, p. 56).

Para tanto, o brincar permite que a criança se desenvolva de forma mais completa, pois esse tipo de atividade lúdica promove, significativamente, novas experiências afetivas, cognitivas e sociais dentro de um ambiente escolar saudável, seguro 
e aconchegante. Desse modo, o brincar facilita a compreensão da realidade, pois imita o real, proporciona experiências que envolve a participação do indivíduo exigindo dele a criatividade, a percepção lógica, além do desafio mental de traçar estratégias para chegar à resolução e conclusão da atividade proposta.

À vista disso, o desenvolvimento humano é um processo longo e gradual de mudanças, no qual o indivíduo se constrói ativamente a partir das relações que estabelece com os ambientes físicos e sociais. Diante disso, Jean Piaget (1979), na sua teoria do desenvolvimento humano, defende a ideia de que:

O desenvolvimento tem base genética, caráter Universal e independente da aprendizagem. Para aprender, a criança precisa estar pronta, isto é, ter uma maturação biológica para a aquisição de informação de acordo com esta prontidão. A criança que não estiver pronta, não tem repertório para aprender questões além do estágio cognitivo em que se encontra. Para Piaget, a lógica abstrata só se desenvolve mais tarde, já na idade escolar. Exigir sua utilização antes disso seria inútil e até prejudicial (Piaget, 1979, p. 24).

Nesse sentido, todos os aspectos do desenvolvimento humano estão interligados, exercendo influência uns sobre os outros, tornando-os dependentes a ponto de não ser possível a estimulação por área. Dessa forma o estímulo deve ocorrer de simultaneamente.

Assim, uma criança, ao realizar seus primeiros passos, está alcançando um progresso físico e nele se encontram envolvidas qualidades como: persistência, autoconfiança e curiosidade, bem como conceitos quanto à distância, firmeza dos objetivos utilizados como apoio e outros. Percebe-se que esse avanço ocorre após várias tentativas em que todos os aspectos citados foram envolvidos numa cadeia de ação e reação.

Para tanto, a criança é um ser em transformação e toda a experiência que adquire no meio social favorece o seu desenvolvimento pessoal, social e escolar. Para tanto, é preciso compreender que cada criança é única, mas que precisa estar sempre em constantes processos de interação, pois é por meio desses encontros que surgem as concepções de diferenças e os respeitos às mesmas. Pois:

O desenvolvimento do sujeito humano se dá a partir das constantes interações com o meio social em que vive, já que as formas psicológicas mais sofisticadas emergem da vida social. Assim o desenvolvimento do psiquismo humano é sempre mediado pelo outro (outras pessoas do grupo cultural), que indica, delimita e atribui significados à realidade (Rego, 2011, p. 61).

As atividades infantis precisam ser essencialmente lúdicas (e não competitivas) e terem como função primordial a descoberta do mundo que as rodeia. É necessário entender que a criança se desenvolve brincando, e o primeiro objeto de referência para estas atividades é o corpo da mãe e do pai, pois é através deles que a criança descobre seu próprio corpo e vai adquirindo as primeiras noções de equilíbrio e segurança.

Nesse sentido, com o passar do tempo, a criança utiliza-se de símbolos e regras em seus jogos, transformando objetos e redefinindo suas funções. Acerca disso, Piaget (1979, p. 28) argumenta que: “O desenvolvimento é visto como um processo maturacional que ocorre antes da aprendizagem, criando condições para que esta ocorra. Precisa haver um determinado nível de desenvolvimento para que certos tipos de aprendizagem sejam possíveis".

Em suma, é sabido que logo nos primeiros meses de vida, há a predominância dos jogos de exercício sensório-motor, que consistem na repetição de gestos e movimentos simples, com valor exploratório; do segundo ao sexto ano de vida, o jogo simbólico, ou seja, jogo de ficção, imaginação ou imitação; e por volta dos sete anos até os doze anos, o jogo de combinações sensório-motor, intelectuais e regulamentadas, quer por um código transmitido de geração em geração, quer por acordos momentâneos. 


\section{O Brincar por Meio do Lúdico de Forma Inclusiva}

Os jogos, os brinquedos e as brincadeiras sempre tiveram um lugar importante na vida de toda criança, exercendo um papel primordial no seu desenvolvimento. Desse modo, desde os povos mais antigos aos mais modernos, todos tiveram e ainda têm seus modos de brincar, assim, as brincadeiras são frutos de um caráter sócio-histórico e cultural das comunidades. Acerca disso, Café (2018, p. 8) ressalta:

A manifestação lúdica sempre esteve presente nas atitudes e significações do fazer humano e, sempre foi considerada tão necessária quanto o trabalho para sua existência. O homem sempre se alimentou do útil e do supérfluo ao mesmo tempo, com a preocupação da sobrevivência, ou da diversão, ou melhor, sem estabelecer valores diferentes entre um e outro. Nesse sentido, pode-se entender que a ludicidade também é parte natural da cultura, vivenciada em momentos indistintos, desde as sociedades mais primitivas e/ou tradicionais.

Nesse sentido, o homem deve utilizar o lúdico como um instrumento de inclusão, visto que o brincar vem acompanhando sua evolução, sendo modificado com o passar do tempo e acompanhado as mudanças das sociedades e das culturas contemporâneas.

À vista disso, a motivação inclusiva pode ser interna quando leva o indivíduo a buscar e superar o feedback recebido em função do que faz para enfrentar esses desafios repercutindo em seu conceito sobre sua competência, suas habilidades, sua eficácia e, portanto, em sua capacidade para iniciar ações relevantes para sua vida.

Para tanto, o interesse dos pais, bem como o próprio aluno, forma uma mescla de agentes diretamente ligados à aprendizagem, pois, ambos anseiam pelo sucesso escolar dos seus. Logo, os pais devem ajudar seus filhos em todas as fases da escolarização, fazendo um acompanhamento frequente e buscando extrair o que aprendeu na escola de modo que o ajude a aplicar conhecimentos na rotina do dia a dia, mesmo que não sejam alfabetizados, é ideal que busquem ajuda e que, também, incentivem o prosseguir de seus filhos na educação.

Neste contexto, faz-se essencial discutir, brevemente, acerca da importância do psicopedagogo no ambiente escolar. O profissional em psicopedagogia é aquele que faz a ponte entre a família e a escola para que haja harmonia e a participação dos responsáveis na escolarização dos filhos. Quanto a isso, Barbosa (2006) define:

A Psicopedagogia é a área que está em parceria com a família e a escola para enfrentar desafios relacionados com o processo de aprendizagem, procurando compreender as dificuldades; o que se aprende; o processo ensino/ aprendizagem e agir sobre estes aspectos de forma a proporcionar o avanço da prática educativa (Barbosa, 2006, p.123).

Acerca disso, além do distanciamento de algumas famílias da escola outro problema que afeta a aprendizagem na educação infantil é a indisciplina. Esta, além de atrapalhar o desenvolvimento de alguns alunos, cria uma barreira na relação professor-aluno interferindo diretamente na aprendizagem e no equilíbrio de toda uma sala de aula.

Ao explorar os mais diversos jogos didáticos em sala de aula, tanto os lógicos como os afetivos, e integrá-los à linguagem oral e a escrita, a aprendizagem tende a tornar-se mais atrativa, mantendo o aluno atento às aulas e incentivando-os ao espírito de união, cooperação e reciprocidade consigo e com o outro.

Em seu estudo, Almeida (1974, p. 25) argumenta: “Os jogos não são apenas como uma forma de desabafo ou entretenimento para gastar a energia das crianças, mas meios que enriquecem o desenvolvimento intelectual”. Logo, os jogos no contexto educacional só podem ser situados corretamente a partir da compreensão dos fatores que colaboram para uma aprendizagem efetivamente ativa. No que se refere aos jogos, estes:

Estão presentes em todas as fazes da vida dos seres humanos, tomando especial a sua existência. De alguma forma o lúdico se faz presente e acrescenta um ingrediente indispensável no relacionamento entre as pessoas, possibilitando que a criatividade aflore (Rojas, 2006, p. 19). 
Mais do que o jogo propriamente dito, o que proporciona um bom aprendizado é a discussão e a troca com o professor e com os colegas, pois esse ato permite a exposição de ideias divergentes, e isso faz que os alunos e o professor repensem, reformulem alternativas, ideias. Esse processo de reformulação promove, também, a análise dos fatos e não simplesmente opiniões que visam o produto final, o acerto. Dessa forma, a interação e a aprendizagem através de jogos tornam-se prazerosas e o aprender brincando é uma das formas mais eficazes para ensino-aprendizagem.

Planejar, executar, corrigir e avaliar podem, muitas vezes, trazer desconforto ao professor, uma vez que ele precisará sair do comodismo de metodologias tradicionalistas, enraizadas nos sistemas escolares. Por isso, ao usar os jogos e outras propostas metodológicas este profissional estará, também, motivando os alunos a participarem, a se empenharem nas atividades e, esse ato, pode motivá-lo a sempre buscar ressignificar suas metodologias.

Nas Escolas de Educação Infantil o lúdico não é trabalhado como estratégia de aprendizagem, mas apenas como atividade recreativa, sem conteúdo formativo. Logo, há uma necessidade premente de descobrir a importância do lúdico na educação, trabalhando a atividade com a faixa etária correspondente à criança que está sendo atendida. De acordo com Ramos (2011):

É interessante ressaltar que a utilização de recursos lúdicos no processo de aprendizagem exige uma interpretação por parte do educador das teorias que tratam a psicologia do desenvolvimento humano. Portanto, cabe aos professores que se interessam pelo uso das atividades lúdicas obterem o conhecimento de tais teorias e de como praticá-las. Uma vez que estas consideram o desenvolvimento humano como um processo natural e social. Não seria o fato de simplesmente utilizar tais métodos de forma aleatória, sem se preocupar com os resultados, mas, usá-las consciente de que o método será eficaz à produção do conhecimento (Ramos, 2011, p.15).

Deve-se nomear, portanto, a brincadeira de modo adequado e referente à época de vida da criança, trabalhando o seu desenvolvimento motor, cognitivo e emocional a partir das necessidades lúdicas necessárias, também, ao atendimento das suas necessidades pessoais, sociais e científicas.

\section{Resultados}

A pesquisa constatou após a análise das literaturas, que na contemporaneidade, infelizmente, muitas instituições de ensino da Educação Infantil se prendem às atividades arcaicas e se esquecem dos processos inclusivos, permanecendo com o uso de metodologias ultrapassadas, ou seja, utilizando-se de atividades repetitivas e, em muitos casos, descontextualizadas, tendo apenas como finalidade o desenvolvimento da coordenação motora por meio do treinamento manual de objetos e conceitos memorizados. Desse modo:

Brincar é sem dúvida uma forma de aprender, mas é muito mais que isso. Brincar é experimentar-se, relacionar-se, imaginar-se, expressar-se, negociar, transformar-se. Na escola, o despeito dos objetivos do professor e do seu controle, a brincadeira não envolve apenas a atividade cognitiva da criança. Envolve a criança toda. É prática social, atividade simbólica, forma interação com o outro. É criação, desejo, emoção, ação voluntária (Fontana; Cruz, 1997, p. $115)$.

Conforme as ideias de Oliveira (2002), os processos que utilizam o jogo na construção de conhecimentos são fundamentais para a educação e o desenvolvimento pleno na infância. Com isso, o jogo e a criança caminham unidos com o propósito de fixar o conhecimento na criança como um ser que brinca, e carrega consigo brincadeiras, saberes e conceitos que se renovam no cotidiano escolar dia a pós dia, a cada geração.

Nesta propositura, percebe-se que as escolas que utilizam os jogos, os brinquedos e as brincadeiras diariamente em suas atividades educacionais, acabam desenvolvendo o cunho lógico, físico das crianças com base no processo de construção 
de conhecimentos, propiciando a sociabilidade, e a criatividade, bem como a formulação e a reformulação de concepções sobre as vivências que cercam cada criança. Nesse sentido, atividades lúdicas no ensino precisam:

Conduzir a criança à busca, ao domínio de um conhecimento mais abstrato misturando habilmente uma parcela de trabalho (esforço) com uma boa dose de brincadeira transformaria o trabalho, o aprendizado, num jogo bem sucedido, momento este em que a criança pode mergulhar plenamente sem se dar conta disso (Almeida, 2003, p. 60).

Nesse viés, as práticas pedagógicas institucionais devem investir no desenvolvimento de jogos e brinquedos com o intuito de garantir o equilíbrio de esforço e de deleite no brincar de forma didática e orientada. E, para que aconteça uma educação lúdica, os docentes precisam a todo tempo se atualizarem e estarem preparados para realizá-la dentro dos espaços escolares para que, assim, a criança sinta gosto no ato de estudar e de buscar os saberes num processo construtivo, participativo e desafiador nas escolas.

De modo geral, é preciso recuperar o verdadeiro sentido da palavra "escola": lugar de alegria, prazer intelectual, satisfação. É preciso também repensar a formação do professor, para que reflitam cada vez mais sobre a sua função (consciência histórica) e adquira cada vez mais competência, não só em busca do conhecimento teórico, mas numa prática que se alimentará do desejo de aprender cada vez mais para poder transformar (Almeida, 2003, p. 64).

Acerca disso, as práticas pedagógicas mediadas pela ludicidade dos jogos são indispensáveis à Educação Infantil e os professores precisam valorizá-las com a utilização de procedimentos lúdicos com a garantia de um desenvolvimento pleno e contínuo, introduzindo-o na prática escolar cotidiana, pois sempre irá existir uma ligação forte entre infância, brincadeiras, jogos brinquedos e educação. Desse modo, essa ligação auxilia no processo de desenvolvimento intelectual, cultural, emocional e afetivo, favorecendo a autonomia, a responsabilidade e a sociabilidade.

Em seu estudo, Oliveira (1996, p. 26) aponta que:

A possibilidade de apropriação de conhecimentos se faz presente, nas interações sociais, desde que a criança vem ao mundo. Sendo assim, menosprezar a capacidade de elaboração subjetiva de cada ser humano ou a responsabilidade de instituição de educação infantil frente à gama de conhecimentos que serão colocados à disposição das crianças significa, no mínimo, empobrecer o universo infantil.

Para tanto, desde o seu nascimento, a criança interage de diversas formas no ambiente em que se estabelece e vive. Nesse processo de interagir com o meio, com outros indivíduos e ao dividir o mesmo ambiente e trabalhar com brinquedos com outras crianças, o conhecimento vai se construindo, apesar de existirem, ainda, nas escolas a construção do conhecimento de forma individual e social. Diante disso, Hatano (1993) em seus escritos, acaba criticando a forma rígida da construção individual e social dos conhecimentos ao destacar os pontos positivos da adoção de práticas didáticas e posturas mais flexíveis:

Arguir que o conhecimento é individualmente construído não é ignorar o papel das outras pessoas no processo de construção. Similarmente, enfatizar o papel das interações sociais e/ou com os objetos na construção do conhecimento, não desmerece a crucial importância da orientação a ser dada pelo professor (Hatano, 1993 p. 163).

Logo, o processo de interação social que envolve a criança e as suas funções psicológicas de percepção das coisas de modo categorial, as mensagens guardadas e transmitidas pela memória e pela lógica da imaginação criadora, trabalham no processo sociointeracionista da aprendizagem, que por meio do ensino e desenvolvimento de atividades didáticas, proporcionam o desenvolvimento de habilidades que nos possibilitam a aprendizagem, a interação e o desenvolvimento.

No entanto, para acontecer esse processo de interação, é preciso ensinar de maneira agradável, propondo as crianças jogos e brincadeiras, para fixar a atenção da criança pelo objeto, ou seja, o brinquedo nos processos de construção de conhecimento. Ainda, vale salientar, que a escola e os professores que trabalham com a etapa da Educação Infantil precisam, 
de forma regular, planejar e acompanhar o processo educacional os alunos, bem como desenvolver autoavaliações as interações acerca das práticas pedagógicas desenvolvidas.

Perante esses conceitos, defende-se que a interação é um meio que exige de todos os que compõem a educação os procedimentos de intervenções, que devem buscar unir os diferentes tipos de conhecimentos proporcionados pelos jogos, brinquedos e pelas brincadeiras, promovendo experiências de maneira interacional e lúdicas.

\section{Discussões}

A brincadeira de forma inclusiva promove a autoestima das crianças, auxiliando-as a vencerem as dificuldades de aprendizagem, de forma progressiva e por meio de metodologias diferenciadas no processo de aquisição de novos saberes com criatividade e aprimoramento de conhecimentos já assimilados anteriormente durante o dia a dia.

De acordo com esse pensamento, Oliveira (2002) ressalta que a brincadeira é um meio primordial para o desenvolvimento da criança pequena que ainda se encontra no processo de desenvolvimento psicológico, auxiliando-a na capacidade de se expressar com diferentes meios, isto é, a linguagem, a imagem, e os argumentos perante os confrontos de papéis que neles se estabelecem em situações corriqueiras que em alguns casos tratam da estrutura socioemocional e da afetividade.

Assim, brincar leva a criança a adquirir concepções e estratégias que a ajudarão a viver no mundo competitivo, trazendo vitórias e derrotas como ensinamentos na fundamentação de afetos, e nas explorações de habilidades, ajudando, também, as crianças a assumirem seus vários papéis enquanto protagonistas da construção de competências cognitivas e interativas.

É, pois, no âmbito das brincadeiras que observamos os diferentes tipos de jogos, que têm como finalidade desenvolver o raciocínio lógico, trabalhar as relações de competitividade perante as atividades lúdicas, com o auxílio de brinquedos, idealizando recursos para a alocação de conhecimentos e a construção de atividades, não só nas salas de aulas, mas em ambientes que é possível trabalhar com o corpo, por meio de ritmos musicais e movimentos dos membros corporais. Vale ressaltar, também, que esse método provoca na criança o ânimo para aprender, e vivenciar de forma constante o que se aprendeu dentro das relações harmoniosas entre o meio e o indivíduo.

Muitos pesquisadores do tema abordado nessa pesquisa defendem a importância do jogo como prática inovadora à educação, afim de desenvolver na criança características diversas mediadas pelas atividades lúdicas. Diante disso, Sampaio (1984, p. 17) argumenta que:

O brinquedo faz com que a criança pense e desenvolva suas capacidades criadoras. Com seus amigos, estabelece contatos sociais, ampliando seu campo de atuação, vivenciando atitudes diferentes e avaliando suas possibilidades como participante de um grupo. O brinquedo tem importância decisiva no desenvolvimento, contribuindo positivamente para realização de cada criança.

Nesses moldes, o processo educativo deve buscar o modo mais saudável de aprender, dependendo da realidade local, no intuito de favorecer as crianças uma interação motivadora de forma lúdica, que garanta a sua felicidade, aprendizado, prazer, e satisfação de forma equilibrada proporcionando o desenvolvimento físico, pessoal, cognitivo, motor e, acima de tudo, o bom desenvolvimento psicológico.

É no brincar e no jogar que as crianças ordenam e reordenam o que está ao seu redor, adquirindo saberes e ressignificando atitudes e valores, presentes no espaço que estão situados. Ainda se defende, cada vez mais, que as brincadeiras e os jogos educativos sejam implantados aos conteúdos diários, permitindo à criança uma aprendizagem significativa e satisfatória. Com isso, a Educação ganha espaço e lugar prazeroso pra quem ensina e quem aprende. Logo: 
Brincando e jogando a criança aplica seus esquemas mentais à realidade que a cerca, aprendendo-a e assimilando-a. Brincando e jogando, a criança reproduz as suas vivências, transformando o real de acordo com seus desejos e interesses. Por isso, pode-se dizer que, através do brinquedo e do jogo, a criança expressa, assimila e constrói a sua realidade (Rizzi; Haydt, 1987, p. 15).

Portanto, a Educação Infantil objetiva o desenvolvimento integral da criança, nos aspectos morais, intelectuais, sociais e outros, os quais, juntos ao apoio familiar e institucional, promovem a ampliação de práticas educativas que consideram a criança e o meio que ela se insere cotidianamente.

A educação infantil, enquanto primeiro momento de contato da criança com a educação escolar, deve despertar no aluno o prazer em realizar atividades que trabalhem com jogos em conjunto com os componentes curriculares básicos e obrigatórios. No entanto, isso também depende da formação docente e do interesse da criança que traz consigo variedades de aprendizados extraescolares.

Nesta perspectiva, o jogo na Educação Infantil proporciona ao docente uma nova forma de mediar os conhecimentos para as crianças que necessitam de condições e propostas pedagógicas como auxílio na aquisição de símbolos e conhecimentos. Nesse sentido, são criados novos significados que se desenvolvem garantindo a racionalidade ao ser humano pelo fato de utilizar o brincar como ferramenta.

O jogo é um elemento promotor da aprendizagem e do desenvolvimento da criança, que nas práticas escolares coloca em prática os saberes adquiridos nas brincadeiras e nos jogos, diante de situações de conflitos, no qual o docente deve criar momentos de brincadeiras em sala de aula de forma lúdica.

O lúdico só terá valor na efetivação da aprendizagem quando o educador e toda comunidade escolar passar a valorizar o brincar, o jogo como elemento importante no processo de aprendizagem; quando reconhecer as limitações do elemento competitivo no brinquedo; equilibrar o brinquedo diretivo e espontâneo; observar o brinquedo infantil para conhecer melhor as crianças e para que possa avaliar até que ponto a atividade está oferecendo prazer à criança (Lyra, 2019, p. 6).

Diante disso, o professor deve estar consciente das orientações a serem explicadas as crianças e auxiliá-las na utilização de brinquedos, incentivando-as a participação dos momentos destinados às brincadeiras. Vale ressaltar que todo jogo é educativo e o educador deverá trabalhar com ponderação para não tornar a sua aplicação intensa e o trabalho educativo como uma simples recreação vazia de conhecimentos.

Segundo Kishimoto (1996), o jogo tem a função didática de trabalhar, com base no lúdico, os diferentes processos de ensino de maneira divertida e prazerosa, permite, ainda, à criança participar das tarefas de forma não forçada e, sim, com motivação. À vista disso, entende-se que a ludicidade aprimora, propicia saberes e tem caráter altamente educativo. Dessa forma, a educação contemporânea, mediante os novos paradigmas da educacionais, é desafiada a promover um trabalho pedagógico baseado na logicidade e no prazer dos movimentos corporais mediado pelas brincadeiras e pelos jogos.

Portanto, o desenvolvimento da criança só acontece com a cooperação e o trabalho em equipe de todos os entes escolares que compõem a educação infantil, que juntos devem buscar alcançar metas planejadas. Com isso, a criança necessita de orientação técnicas para aprender a ganhar e a perder, e, quando ganhar, nunca menosprezar os que não obtiveram êxito. Logo, o lúdico no ensino possibilita que a criança saiba perder sem se achar inferior ou sem se sentir diminuído, deixando prevalecer o respeito e a amizade pelo adversário numa relação social de interação.

\section{Considerações Finais}

Tendo como base esta pesquisa, podemos afirmar que, por meio de jogos didáticos, a criança aprimora a atenção, a afetividade, a interação, a concentração e a sua psicomotricidade, que são elementos indispensáveis à sua vida social. Desse 
modo, ao brincar e jogar, o educando se envolve de forma prazerosa no qual percebe-se em seu olhar um sentimento de prazer e emoção. Nessa lógica, por meio do brincar e do jogar, a criança passa pelo processo de desenvolvimento até adquirir, por meio da experiência, os valores e conhecimentos.

Dessa forma, é de fundamental importância que os professores mudem as práticas docentes tradicionais e utilizem os jogos, os brinquedos e as brincadeiras como recurso no processo de ensino e de aprendizagem, pois esses recursos proporcionam um clima de entusiasmo e, consequentemente, acabam acionando e ativando as funções neurológicas e físicas, estimulando o pensamento e a parte física do corpo dos discentes, além de contribuir com a construção de um cidadão crítico e reflexivo.

A partir dessas constatações, afirmamos a necessidade de estudos que contemplem o desenvolvimento de metodologias ativas para o ensino-aprendizagem na Educação Infantil pautado nos jogos e na ludicidade, que colaborem com o desenvolvimento de habilidades e competências para a formação de alunos críticos, reflexivos e autônomos. Esperamos que esta proposta possa contribuir para indagações existentes, assim como servir de fundamentação e provocação para outras pesquisas acadêmicas.

\section{Agradecimentos}

Agradecemos a Deus pelo dom da vida.

\section{Referências}

Almeida, P. N. (1974). Educação lúdica: técnicas e jogos pedagógicos. (9a ed.), Loyola.

Barbosa, L. M. S. (2006). Psicopedagogia: um diálogo entre a psicopedagogia e a educação. Curitiba: Bolsa Nacional do Livro.

Bossa, N. A. (2007). A Psicopedagogia no Brasil: contribuições a partir da prática. Artmed.

Brasil. (1996). Lei das Diretrizes e Bases da Educação Nacional. MEC/SEF.

Brasil. (1998). Referencial Curricular Nacional para a Educação Infantil. MEC/SEF.

Café, A. B. (2018). O Jogo Lúdico na Escola de Ensino Básico. LICERE - Revista Do Programa De Pós-graduação Interdisciplinar Em Estudos Do Lazer, 21(4), 1-25. https://doi.org/10.35699/1981-3171.2018.1923.

Ferreira, L. G. (2020). Formação de professores e ludicidade: reflexões contemporâneas num contexto de mudanças. Revista De Estudos Em Educação E Diversidade - REED, 1(2), 410-431. https://doi.org/10.22481/reed.v1i2.7901.

Fontana, R., \& Cruz, N. (1997). Psicologia e trabalho pedagógico. Atual.

Gil, A. C. (2002). Como elaborar Projetos de Pesquisa. (4a ed.), Atlas.

Hatano, G. (1993). Time to Merge Vygotskian and Constructivist Conceptions of Knowledge Acquisition. In Forman, E.; Minick, N. e Stone, C. (Eds.) Contexts for Learning: Sociocultural Dynamics in Children's Development. New York: Oxford University Press.

Kishimoto, T. M. (1996). Jogo, brinquedo, brincadeira e a educação. Cortez.

Lyra, h. J. (2019). A importância de se trabalhar com a ludicidade na educação infantil reconsiderações. SAPIENS - Revista De divulgação Científica, 1(1). Recuperado de https://revista.uemg.br/index.php/sps/article/view/3439.

Medeiros. J. B. (2000). Redação cientifica: A prática de fichamentos, resumos e resenhas. (4a ed.), Atlas.

Negrine, A. (1996). Aprendizagem e desenvolvimento infantil. Prodil.

Oliveira, Z. M. R. (1996). Educação infantil: muitos olhares. (3a ed.), Cortez.

Oliveira, Z. M. R. (2002). Educação Infantil: fundamentos e métodos. Cortez.

Piaget, J. (1979). A Construção do real na criança. Zahar.

Ramos, M. C. A. L., \& WEIDUSCHAT, I. (2002). Jogar e brincar: representando papéis, a criança constrói o próprio conhecimento e, consequentemente, sua própria personalidade. Revista Leonardo, 1, 1-10. 
Research, Society and Development, v. 10, n. 13, e234101321242, 2021

(CC BY 4.0) | ISSN 2525-3409 | DOI: http://dx.doi.org/10.33448/rsd-v10i13.21242

Rego, T. C. (2011). Vygotsky: uma perspectiva histórico-cultural da educação. (22a ed.), Vozes.

Rizzi, L., \& Haydt, R. C. C. (1986). Atividades lúdicas na educação da criança: subsídios práticos para o trabalho na pré-escola e nas series iniciais do 1. grau: livro do professor. Ática.

Rojas, J. (2002). O lúdico na construção interdisciplinar da aprendizagem: uma pedagogia do afeto e da criatividade na escola. Rio de Janeiro: ANPED.

Sampaio, V. R. C. (1984). Creche: atividades desenvolvidas com a criança. $E B M$.

Severino, A. J. (2007). Metodologia do Trabalho Científico. Cortez.

Velasco, C. G. (2006). Brincar: o despertar psicomotor. Sprint. 